\title{
Challenges for NHS hospitals during covid-19 epidemic
}

\author{
Healthcare workers need comprehensive support as every aspect of care is reorganised
}

\author{
John Willan consultant haematologist ${ }^{1}{ }^{2}$, Andrew John King consultant haematologist ${ }^{3}$, Katie Jeffery \\ consultant microbiologist ${ }^{2}$, Nicola Bienz consultant haematologist ${ }^{1}$
}

${ }^{1}$ Frimley Health NHS Foundation Trust, Wexham Park, Slough, Berkshire, UK; ${ }^{2}$ Oxford University Hospitals NHS Foundation Trust, Churchill Hospital, Oxford, UK; ${ }^{3}$ Cambridge University Hospitals NHS Foundation Trust, Cambridge, UK

\begin{abstract}
Delivery of every aspect of care by all clinical and non-clinical departments in the UK's NHS is being reassessed and fundamentally reorganised in the expectation of an imminent surge of patients with covid-19. ${ }^{1}$ Modelling of the outbreak assumes an infection fatality ratio of $0.9 \%$ and a hospital admission rate of $4.4 \%$, with $30 \%$ of those admitted requiring critical care or extracorporeal membrane oxygenation. ${ }^{23}$ The increased demand on healthcare services will be compounded by the apparent increased risk of infection among healthcare workers, ${ }^{4}$ and staff absences because of illness or self-isolation may be as high as $20 \% .^{11}$ The government has made recommendations for case isolation, social distancing, and household quarantine intended to reduce the peak of the epidemic and the resulting pressure on NHS hospitals. ${ }^{56}$
\end{abstract}

\section{Workforce}

Over the next four weeks thousands of medical students are likely to graduate early and be allowed to begin work as junior doctors. Doctors who have retired within the last three years are being asked to consider returning to work. Those working in education, research, or inspection are encouraged to return to clinical duties; funding bodies, including the Wellcome Trust, have agreed to support this. ${ }^{7}$ Within hospitals, clinical staff may be redeployed from specialties to the areas of greatest need, with additional training provided rapidly, as necessary. The government also has the possibility of calling on the logistical and medical expertise within the army to support hospitals.

Doctors in training face substantial disruption, including the loss of training opportunities, failure to rotate, and the cancellation of postgraduate exams. It is important that their career progression is not affected in the longer term.

In responding to unprecedented hospital demand, clinicians will find it necessary to deviate from the established standards for the management of most conditions. Some patients will be harmed-for example, because of undetected deterioration of a longstanding health condition or cancellation of planned surgery. Many doctors may also be asked to practise outside their defined areas of expertise or to exceed their contracted hours. Some groups of doctors may lack confidence in their clinical skills because they have moved into a very different clinical role, graduated early, or retired and not worked for some years.

Support from healthcare authorities, regulators, and the government for doctors making difficult clinical decisions is vital, as is the understanding that they will be supported in the event of adverse outcomes. The statement from the General Medical Council, the NHS, and the Academy of the Medical Royal Colleges on 12 March supporting doctors in decision making within the context of a covid-19 epidemic is welcome. ${ }^{8}$

\section{Infrastructure}

Medical beds and critical care capacity require substantial expansion, and this is already being enabled by cancelling elective work, repurposing operating theatres, and commissioning use of private facilities. ${ }^{1}$ Increased support for discharge of existing patients to the community is also underway. Routine outpatient work will be scaled down to reduce the burden on the hospital and the infection risk to the patients from contact with more people. When possible, appointments are being moved to telephone or video calls to avoid unnecessary visits. Similarly, some hospitals are considering off-site phlebotomy centres so patients avoid visiting the main hospital site; medications may be delivered by courier. Patients who are immunosuppressed and those with cancer are likely to be at particular risk of severe complications of covid-19. ${ }^{9}$ Temporary delays or reductions in chemotherapy intensity may protect those patients and reduce the likelihood of their admission. Individual decisions should be taken regarding the benefits and risks of continuing non-life saving chemotherapy. ${ }^{10}$

Illness and self-isolation of workers in administrative and managerial departments are likely to place increased burdens and stresses on frontline healthcare workers. Tasks such as ensuring safe staffing levels, communicating administrative information to patients at home, and reorganising outpatient 
clinic lists must not take healthcare workers away from direct clinical duties.

To ease these burdens and to support the clinical activities, hospitals should consider bringing in teams of highly trained professionals, such as project managers, from outside the NHS to work alongside current managers and administrators. They would have the expertise to deliver logistics solutions to hospitals responding to the epidemic, enabling more efficient healthcare delivery.

The UK government says that the country is now on a war footing. Much of Europe is in lockdown, and major public events have been cancelled. It is impossible to know what the next weeks and months may bring. In this new normal, it is important for those in charge to be mindful of the strain that every healthcare worker will be under and the mental, emotional, and physical risks involved in responding to an unprecedented crisis. NHS staff are its most valuable asset and will react with energy and flexibility, but urgent consideration must also be given to supporting their health and wellbeing-for the benefit of all.

Competing interests: We have read and understood BMJ policy on declaration of interests and have no relevant interests to declare.

Provenance and peer review: Commissioned; not externally peer reviewed.

1 NHS England. Next steps on NHS response to COVID-19: Letter from Sir Simon Stevens and Amanda Pritchard, 17 Mar 2020. https://www.england.nhs.uk/coronavirus/wp-content/ uploads/sites/52/2020/03/20200317-NHS-COVID-letter-FINAL.pdf
2 Verity R, Okell LC, Dorigatti I, Winskill P, Whittaker C, Imai N, et al. Estimates of the severity of COVID-19 disease [preprint]. medRxiv 2020.03.09.20033357. 10.1101/2020.03.09.20033357

3 Ferguson NM, Laydon D, Nedjati-Gilani G, Imai N, Ainslie K, Baguelin M, et al. (2020). Imperial College COVID-19 response team. Impact of non-pharmaceutical interventions (NPIs) to reduce COVID19 mortality and healthcare demand. 2020. www.imperial.ac.uk/ media/imperial-college/medicine/sph/ide/gida-fellowships/Imperial-College-COVID19-NPImodelling-16-03-2020.pdf

4 Guan W-J, Ni Z-Y, Hu Y, etal. China Medical Treatment Expert Group for Covid-19. Clinical characteristics of coronavirus disease 2019 in China. N Engl J Med 2020. [Epub ahead of print]. 10.1056/NEJMoa2002032. 32109013

5 Public Health England. Guidance on social distancing for everyone in the UK and protecting older people and vulnerable adults. 16 Mar 2020. https://www.gov.uk/government/ publications/covid-19-guidance-on-social-distancing-and-for-vulnerable-people/guidanceon-social-distancing-for-everyone-in-the-uk-and-protecting-older-people-and-vulnerableadults

6 Public Health England. Stay at home: guidance for households with possible coronavirus (COVID-19) infection. Updated 18 Mar 2020. https://www.gov.uk/government/publications/ covid-19-stay-at-home-guidance/stay-at-home-guidance-for-households-with-possiblecoronavirus-covid-19-infection

7 Wellcome Trust. Coronavirus (COVID-19): information for grant applicants and grantholders. https://wellcome.ac.uk/grant-funding/guidance/coronavirus-covid-19information-grant-applicants-and-grantholders

8 NHS England, NHS Improvement. Letter: supporting doctors in the event of a COVID-19 epidemic in the UK, 12 Mar 2020. https://www.england.nhs.uk/coronavirus/publication/ letter-supporting-doctors-in-the-event-of-a-covid-19-epidemic-in-the-uk/

9 Liang W, Guan W, Chen R, etal . Cancer patients in SARS-CoV-2 infection: a nationwide analysis in China. Lancet Oncol 2020;21:335-7. 10.1016/S1470-2045(20)30096-6 32066541

10 Willan J, King AJ, Hayes S, Collins GP, Peniket A. Care of haematology patients in a COVID-19 epidemic. Br J Haematol 2020. 10.1111/bjh.16620 32173855

11 Department of Health and Social Care. Coronavirus action plan: a guide to what you can expect across the UK. 3 Mar 2020. https://www.gov.uk/government/publications/ coronavirus-action-plan/coronavirus-action-plan-a-guide-to-what-you-can-expect-acrossthe-uk]

Published by the BMJ Publishing Group Limited. For permission to use (where not already granted under a licence) please go to http://group.bmj.com/group/rights-licensing/ permissions 